\title{
MATHEMATICAL MODEL OF THE THERMAL-AIR REGIME OF A VENTILATED ATTIC
}

\author{
Jerzy Zbigniew PIOTROWSKI, Anatoliy STROY, Marianna OLENETS \\ Faculty of Civil Engineering and Environment, Kielce University of Technology, \\ al. Tysiaclecia Państwa Polskiego 7, 25-314 Kielce, Poland
}

Received 28 Oct 2012; accepted 08 Jan 2013

\begin{abstract}
This paper presents the developed mathematical models that characterize the thermal-air regime of a ventilated attic in the summer and winter seasons. The relevance of the mathematical models was shown and examples of applying these models to solve some engineering problems were presented. Mathematical models can be used to analyze and evaluate changes in the temperature and heat flux (the radiant and convective component) along the air movement in the attic and to select the materials for the roof and floor, as well as for the calculation of ventilation for different climatic conditions.
\end{abstract}

Keywords: mathematical model, heat transfer process, thermal-air regime, heat flow, ventilated attic.

\section{Introduction}

An attic is one of the necessary building elements. The airspace in the attic is limited by the attic floor on the bottom and the roof on the top. The roof serves to protect the building from weather effects. Roofs are divided into flat and pitched. The latter are divided into the following types: gable roofs, hipped roofs (mono-pitched roof, hipped roof with one straight gable, hipped roof with all the surfaces sloping) and a mansard or Dutch roof. The gable and hipped roof with all the surfaces sloping are the most common. However, mono-pitched and lean-to roofs have recently become rather popular.

At the same time, attics can be divided into walkable, crawl space and impassable (non-walkable). In these cases an attic air space (air layer or air duct) will have a different height $h$ (Fig. 1).

An unfavourable microclimate forms in the upper floors of a built-up roof (one without air space) during the summer, which makes the roof type the least effective (Chwieduk 2011; Sunwoo et al. 2009; Susantia et al. 2011).

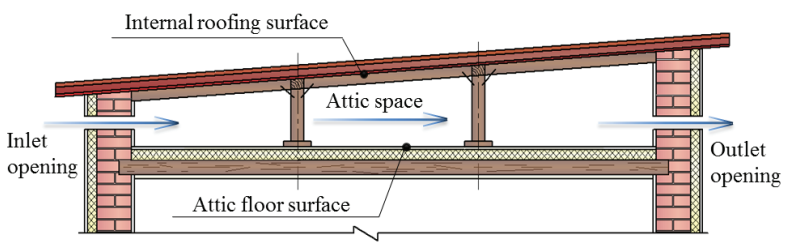

Fig. 1. Scheme of the single-pitched (mono-pitched) attic roof
The influence of the attic air space construction, roof and attic floor material, and other design features on the heat gains into the premises due to the action of solar radiation is not completely clear. One of the most difficult problems that arise during the microclimate formation is the problem of reducing energy consumption and generally the cost of air conditioning for a building's upper floors. To solve this problem, more detailed theoretical and experimental studies are required.

The heat losses of the building's upper floors increase during winter conditions due to the more intensive ventilation of the attic space. In turn, this causes an increase in the heat consumption for room heating. On the other hand, with a decrease in the ventilation of the attic during the cold period, the heat losses are reduced, but the reduction can cause condensation of water vapour on the inner surface of the roof and corrosion of its metal parts. Thus, the air exchange process of the attic is also quite important under winter conditions. An in-depth study of the processes that characterize the thermal and air regime of an attic in the summer and winter periods as well as the development of engineering recommendations will make it possible to reduce the heat gains into the upper floors' premises in the summer and reduce heat losses in the winter.

Analysis of the literature indicates the presence of some significant weaknesses in the research of the thermal and air regimes of an attic. First of all, most authors consider the thermal and air modes of the attic

Corresponding author: Marianna Olenets

E-mail: mari_olensa@mail.ru 
separately. Buga (1987) gives advice about the organization of attic ventilation systems but the calculation method is missing. Attempts to combine and consider the thermal and air regimes in an attic as a whole were made in Nik et al. (2012), Stroy and Piotrowski (2009), Zender-Swiercz and Piotrowski (2010). However, the mathematical model proposed in Zender-Swiercz and Piotrowski (2010), is the rather simplistic, so-called point model. The authors use only a single equation to determine the mean air temperature in the attic which does not take into account the changes of air temperature as it moves along the attic space. In Ciamp et al. (2005), Stroy and Piotrowski (2009), Zender-Swiercz and Piotrowski (2010) the convective and radiative heat transfer processes in the attic have been considered jointly, although it should be noted that the physical phenomena occurring in the convective and radiative heat transfer are quite different. It is inappropriate to combine them at the stage of analysis and theoretical studies.

Attention should be paid to the mathematical model of the thermal regime of the air space in the attic, developed for the summer season and given in Bogoslovsky (1982). The disadvantage of this model is that the heat balance equation for the outer roof surface was derived with the use of the conditional (solar) temperature concept. This approach dramatically reduces the amount of information that can be obtained by solving the mathematical model. Also, the use of approximate values of the heat transfer coefficient near the outer surface of the roof required to determine the solar temperature does not always provide sufficiently reliable results. The author Bogoslovsky (1982) used the simplifying premise that the air flow in the air layer is heating near the roof surface, and cooling near the surface of the floor. In fact, when moving along the duct, the air will be heating up near both of the surfaces. In the compilation of the equations system, the author has adopted a simplifying premise that both of the surfaces' temperatures are unchanged along the length of the attic, i.e. that the surfaces are isothermal. This assumption is the reason for the lack of equality of the heat flows' balance in the example for the calculation of heating which is used in mathematical model (Bogoslovsky 1982) (Fig. 9).

Some authors (Fokin 1973; Pogorzelski 1976) recommend using the Machinskiy equation for the calculation of air heating as it moves along the attic space under winter conditions. When developing this equation, the radiative and convective heat flows are considered together as a radiative-convective heat flow. Furthermore, the simplifying assumption that the air is heated near the one surface, and cooled near the other has been adopted as in reference (Bogoslovsky 1982). The equation proposed by Machinskiy, and Bogoslovsky (1982), Ciamp et al. (2005), Zender-Swiercz and Piotrowski (2010) can, in our opinion, only be used for engineering and some approximate calculations. It does not allow us to analyse the influence of the emissivity of the roof and attic floor surface on the radiative heat transfer process, and the effect of the air velocity on the process of convective heat transfer. Also the condition of the heat balance equality is not met. Based on this information, it can be concluded that for more detailed and deeper studies, there needs to be a more complete mathematical model of heat transfer processes in the attic air space.

Some of the papers (Shimin et al. 2012; Suvash et al. 2010; Winiarski, O’Neal 1996) are also devoted to developing a more complete mathematical model of the thermo-air regime of the attic. However, in Shimin et al. (2012), Suvash et al. (2010) the authors considered only natural convection, i.e. they do not take into account the action of the external forces that cause the movement of air in the attic space. The system of equations (mathematical model) (Winiarski, O’Neal 1996) is not drawn up properly, in particular, Eqns (9) and (21) (Winiarski, O’Neal 1996), which characterize the air heating near the surfaces of the attic.

The objective of this scientific study is to develop a more complete mathematical model and the methodology for calculating the attic thermal mode under the action of gravity and wind pressure, i.e. in the presence of ventilation.

To solve this problem, let us consider the process of air parameters changing in a ventilated attic under winter and summer conditions, in the light of its heating by solar radiation or by heat exchange with air flow.

When developing a mathematical model of thermoair regime, the attic airspace shall be considered as an air channel (air duct) with a known size and a constant velocity of air flow along it.

\section{Mathematical model for winter}

With the aim of analysing the attic thermo-air regime and determining the temperature $T_{x}$, as well as the temperature at the inner surface of the roof $T_{r}$ and the outer surface of the attic floor $T_{f}$ with a different air exchange value (a varying ventilation rate), a physical model of the steady-state process of the heat transfer in the attic with a moving air flow has been developed. It is represented in Figure 2.

The processes of radiative and convective heat transfer in the airspace are considered separately, and the attic space is considered as an air channel (air duct) in which the air enters at one side and comes out the other. The air movement in the attic is motivated by gravity action and wind pressure. Based on this physical model, an equation set (1) (a mathematical model) has been composed.

The first equation of the system (1) describes the heat balance of the outer floor surface and the second equation - the heat balance of the inner roof surface. The third and fourth equations describe the heat balance of 


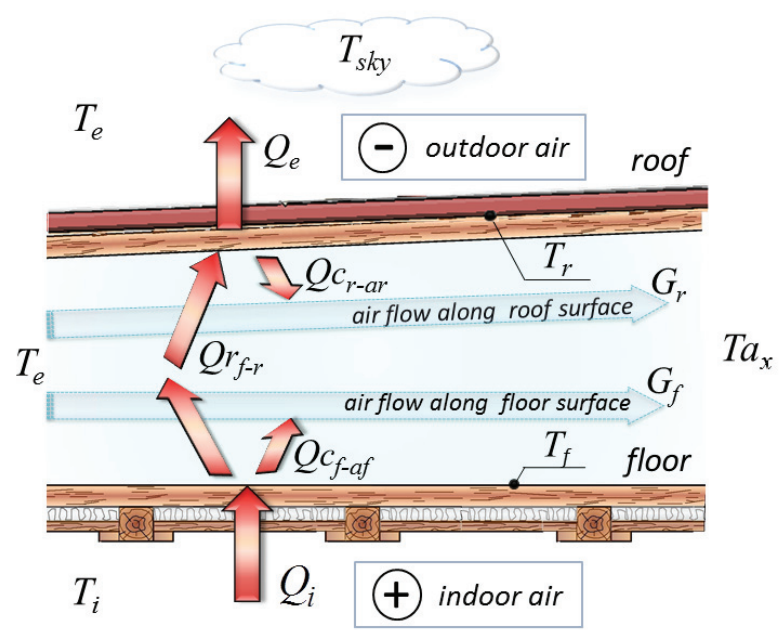

Fig. 2. Scheme of the heat flows in the attic under winter conditions

Note: $Q_{i}$ - heat flow from the room to the attic space; $Q c_{f-a f}-$ convective heat flow from the floor surface to the air near it; $Q r_{f-r}-$ radiative heat flow between the floor and internal roof surface; $Q c_{r-a r}$ - convective heat flow from the internal roof surface to the air near it; $Q_{e}$ - heat flow from the internal roof surface to the outdoor ambient is the sum of the three heat flows $Q_{e}=Q c_{r-e}+$ $Q r_{r-a}+Q r_{r-s k y} ; Q c_{r-e}-$ convective heat flow from the external roof surface to the outdoor air; $Q r_{r-a}$ - radiative heat flow between the external roof surface and surrounding objects; $Q r_{r-s k y}-$ radiative heat flow between the external roof surface and the sky).

the air moving along the corresponding surfaces for a set value of coordinate $\mathrm{x}$. The fifth equation characterizes the motion of air in the attic.

For the derivation of the equations, the following simplifying assumptions were adopted:

1. The stationary problem of the heat transfer under the motion of the air flow in the airspace of the attic is considered;

2. The convective heat transfer coefficients and velocity of the air flow were considered as constant values along the length of the air channel;

3. The roof and attic floor surface areas were accepted as equal. Thus, the proposed equations set has a sufficient degree of accuracy for roofs with a small slope angle;

4. The flow rate $G$ of the air moving along the attic is conventionally divided into two equal flows: the flow of the air near the outer surface of the attic floor $G_{f}$, and the second - the air flow near the inner surface of the roof $G_{r}\left(G_{f}=G_{r}=G / 2\right)$;

5. When determining the value of the heat flow from the internal roof surface to the outdoor ambient $Q_{e}$ outer roof surface, the heat transfer coefficient was assumed according to the European and International Standard (EN ISO 6946 2008). More accurate radiative heat exchange with the sky is considered in references (Berdahl, Fromberg 1982; Nowak 2001).
In the case of a single-pitched roof, the premise that the air moves at a constant rate was adopted. This premise will not make a significant inaccuracy in the calculation results. This premise can be taken with some degree of certainty for hipped roofs.

$$
\begin{aligned}
& U_{i-f}\left(T_{i}-t_{f}(x)\right)=\varepsilon_{f-r} \cdot \sigma\left[\left(\frac{T_{f}(x)+273}{100}\right)^{4}-\right. \\
& \left.\left(\frac{T_{r}(x)+273}{100}\right)^{4}\right]+h c_{f}\left(T_{f}(x)-T a_{f}(x)\right) ; \\
& U_{r-e}\left(\mathrm{~T}_{\mathrm{r}}(x)-\mathrm{T}_{\mathrm{e}}\right)= \\
& \varepsilon_{f-r} \cdot \sigma\left[\left(\frac{T_{f}(x)+273}{100}\right)^{4}-\left(\frac{T_{r}(x)+273}{100}\right)^{4}\right]- \\
& h c_{r}\left(T_{r}(x)-T a_{r}(x)\right) ; \\
& h c_{f}\left(\mathrm{~T}_{f}(x)-T a_{f}(x)\right) b=c G_{f} \frac{d T a_{f}}{d x} ; \\
& h c_{r}\left(\mathrm{~T}_{f}(x)-T a_{r}(x)\right) b=c G_{r} \frac{d T a_{r}}{d x} ; \\
& \left(\sum \xi_{0} \cdot \frac{v_{0}^{2}}{2} \rho_{e}\right)+\left(\sum \xi+\lambda \frac{L}{D_{h}}\right) \frac{v_{m}^{2}}{2} \rho_{m}= \\
& \left(n_{\text {in }}-n_{\text {out }}\right) \frac{v_{w}^{2} \rho_{e}}{2}+\Delta P_{g},
\end{aligned}
$$

where: $U_{i-f}$ - heat exchange coefficient from the indoor air to the attic floor surface; $U_{r-e}$ - heat exchange coefficient from the internal roof surface to the outdoor air; $T_{r, f}$ - temperature at the inner surface of the roof and outer surface of the attic floor; $T_{i, e}$ - temperature of the indoor and outdoor air; $T a_{r, f}-$ air temperature near the inner surface of the roof and the outer surface of the attic floor; $c$ - air specific heat; $\sigma$ - Stefan-Boltzmann constant; $\varepsilon_{f-r}$ - equivalent emissivity; $h c_{r, f}$ - convection coefficient near the inner surface of the roof and outer surface of the attic floor; $G_{r, f}$ - mass air flow near the inner surface of the roof and outer surface of the attic floor; $\Sigma \xi_{o}, \Sigma \xi$ - sum of the local resistance factors of the air opening and air duct (attic, air layer); $v_{w}$ - wind velocity; $\rho_{e}$ - density of the outdoor air; $\rho_{m}-$ main air density in the duct (attic, air layer); $v_{o}$ - air velocity in the ventilation opening; $v_{m}$ - main air velocity in the duct (attic, air layer); $n_{\text {in, out }}$ - aerodynamic coefficient of the inlet and outlet ventilation opening; $\lambda$ - friction factor; $L$ - length of the air duct (attic, air layer); $D_{h}$ - hydraulic diameter; $\Delta P_{g}$ - hydrostatic pressure difference.

When integrating the third and fourth differential equations of set (1), a simplifying assumption that the ratio of the surface temperature to the changes in temperature of the air moving near the surface is a constant $(\Delta T(x) / \Delta T a(x)=d T(x) / d T a(x)=$ const $)$ was accepted. In 
other words, this ratio (the temperature coefficient) does not change along the channel.

The equation set (2), which characterizes the thermal-air regime of the attic space, was obtained after the integration of the third and fourth differential equations from (1).

$$
\begin{aligned}
& U_{i-f}\left(T_{i}-T_{f}(x)\right)=\varepsilon_{f-r} \cdot \sigma\left[\left(\frac{T_{f}(x)+273}{100}\right)^{4}-\right. \\
& \left.\left(\frac{T_{r}(x)+273}{100}\right)^{4}\right]+h c_{f}\left(T_{f}(x)-T a_{f}(x)\right) ; \\
& U_{r-e}\left(T_{r}(x)-T_{e}\right)=\varepsilon_{f-r} \cdot \sigma\left[\left(\frac{T_{f}(x)+273}{100}\right)^{4}-\right. \\
& \left.\left(\frac{T_{r}(x)+273}{100}\right)^{4}\right]-h c_{r}\left(T_{r}(x)-T a_{r}(E)\right) ; \\
& T a_{f}(x)=T_{f}(x)-\frac{T_{f}(x)-T_{e}}{\frac{h c_{f}}{c G_{f}} x \cdot b \cdot A_{t f}} ; \\
& T a_{r}(E)=T_{r}(x)-\frac{T_{r}(x)-T_{e}}{\frac{h c_{r}}{c G_{r}} x \cdot b \cdot A_{t r}} ; \\
& \left(\sum \xi_{o} \cdot \frac{v_{o}^{2}}{2} \rho_{e}\right)+\left(\sum \xi_{j}+\lambda \frac{L}{D_{h}}\right) \frac{v_{m}^{2}}{2} \rho_{m}= \\
& \left(n_{\text {in }}-n_{\text {out }}\right) \frac{v_{w}^{2} \rho_{e}}{2}+\Delta P_{g}
\end{aligned}
$$

where: $A_{t r, f}$ - temperature coefficient for the inner surface of the roof and the outer surface of the attic floor; $b$ - width of the air duct (attic, air layer); $x$ - distance from inlet to an arbitrary point in the air layer (longitudinal coordinate).

The system of Eqns (2) includes the four unknown functions of the temperature and velocity of the air moving in the attic. Two of them are functions of the temperature change of the floor and roof surfaces, and the two others characterize the changes in the air temperature along the length of the attic space. The value of the average air temperature in the attic can be estimated as the arithmetic mean between the two temperatures of the air flows near the roof and floor surface. The mathematical model (2) could be used in the calculation of the specific problems with the assistance of mathematical software, such as MathCAD.

To evaluate the consistency of the simplifying premise $d T(x) / d T a(x)=$ const, which was adopted in the process of integration, a set of Eqns (1) was written in the form of finite differences. In other words, the first four equations of (1) were replaced by six similar equations. As a result, the system of Eqns (3) was obtained.

$$
\begin{aligned}
& U_{i-f}\left(T_{i}-T_{f m}\right) \Delta x b=\varepsilon_{f-r} \sigma\left[\left(\frac{T_{f m}(x)+273}{100}\right)^{4}-\right. \\
& \left.\left(\frac{T_{r m}(x)+273}{100}\right)^{4}\right] \times \Delta x b+h c_{f}\left(T_{f m}-T a_{f m}\right) \Delta x b ; \\
& U_{r-e}\left(T_{r m}-T_{e}\right) \Delta x b=\varepsilon_{f-r} \sigma\left[\left(\frac{T_{f m}(x)+273}{100}\right)^{4}-\right. \\
& \left.\left(\frac{T_{r m}(x)+273}{100}\right)^{4}\right] \Delta x b-h c_{r}\left(T_{r m}-T a_{r m}\right) \Delta x b ; \\
& h c_{f}\left(T_{f m}-T a_{f m}\right) \Delta x b=c \cdot G_{f}\left(T a_{f e}-T a_{f s}\right) ; \\
& h c_{r}\left(T_{r m}-T a_{r m}\right) \Delta x b=c \cdot G_{r}\left(T a_{r e}-T a_{r s}\right) ; \\
& 2 \cdot T a_{f m}-T a_{f e}=T a_{f s} ; \\
& 2 \cdot T a_{r m}-T a_{r e}=T a_{r s},
\end{aligned}
$$

where: $\Delta x$ - iterative procedure step; $T_{r m, f m}$ - temperature at the roof and floor midpoint of the iterative procedure step; $T_{r s, f_{s}}$ - temperature at the roof and floor start point of the iterative procedure step; $T_{r e, f e}$ - temperature at the roof and floor endpoint of the iterative procedure step; $T a_{r m, f m}$ - air temperature near the roof and floor midpoint of the iterative procedure step; $T a_{r s, f s}$ - air temperature near the roof and floor start point of the iterative procedure step; $T a_{r e, f e}$ - air temperature near the roof and floor endpoint of the iterative procedure step.

The calculations using the mathematical model (3) confirmed the ratio $d T(x) / d T a(x)=$ const, and that it does not depend on the coordinate $\mathrm{x}$. Furthermore, it allows the determination of the temperature coefficient $A_{t}$ under a given construction of the roof and floor. A comparative analysis of the results calculated by using the proposed mathematical models (2) and (3) were also performed with the help of MathCAD. Since the results of the comparative calculations were identical, we can conclude that the mathematical model (2) differs from the mathematical model (3) by only the form of notation.

Results, which can be obtained with the use of the mathematical model (2) or (3), were compared with the calculation results of the ventilated attic space (Fokin 1973) to evaluate the reliability of those models. In particular, the values of the heat fluxes and air temperature in the attic, which were calculated using the Eqns (2) and (3), have been compared with the data given in reference (Fokin 1973). The comparison results of a heat flow value and changes in the air temperature along the attic channel are shown in Figure 3 and Figure 4 respectively under the following initial data (Table 1).

Numerical values of heat flows determined according to the initial data (Fokin 1973), under a mean air temperature $T a_{m}=-6.96{ }^{\circ} \mathrm{C}$ using the following equations:

- Heat flow from the premises to the attic space

$$
\begin{aligned}
& Q_{i-a}=U_{i-a} \cdot a \cdot b\left(T_{i}-T a_{m}\right)=7 \cdot 0.8(15.5- \\
& (-6.96))=88 \mathrm{~W} ;
\end{aligned}
$$


Table 1. Initial data for comparative calculations of attic space (according to Fokin)

Heat exchange coefficient from the indoor air to the attic floor surface $\left(\mathrm{W} / \mathrm{m}^{2} \cdot \mathrm{K}\right)$

$\mathrm{U}_{i-f}=0.75$

Heat exchange coefficient from the internal roof surface to the outdoor air $\left(\mathrm{W} / \mathrm{m}^{2} \cdot \mathrm{K}\right)$

$\mathrm{U}_{r-e}=3.32$

Indoor air temperature $\left({ }^{\circ} \mathrm{C}\right)$

$\mathrm{T}_{i}=15.5$

Outdoor air temperature $\left({ }^{\circ} \mathrm{C}\right)$

$\mathrm{T}_{e}=-8.5$

Inlet aerodynamic coefficient

$\mathrm{n}_{\text {in }}=0.6$

Outlet aerodynamic coefficient

$\mathrm{n}_{\text {out }}=-0.4$

$\mathrm{v}_{w}=2.7$

Cross sectional area of the inlet and outlet ventilation opening $\left(\mathrm{m}^{2}\right)$

$\mathrm{A}_{o}=0.012$

Air duct hydraulic diameter (m)

$\mathrm{D}_{h}=0.19$

Length of the air duct (m)

$\mathrm{L}=7$

Width of the air duct (m)

$\mathrm{b}=1$

Emissivity

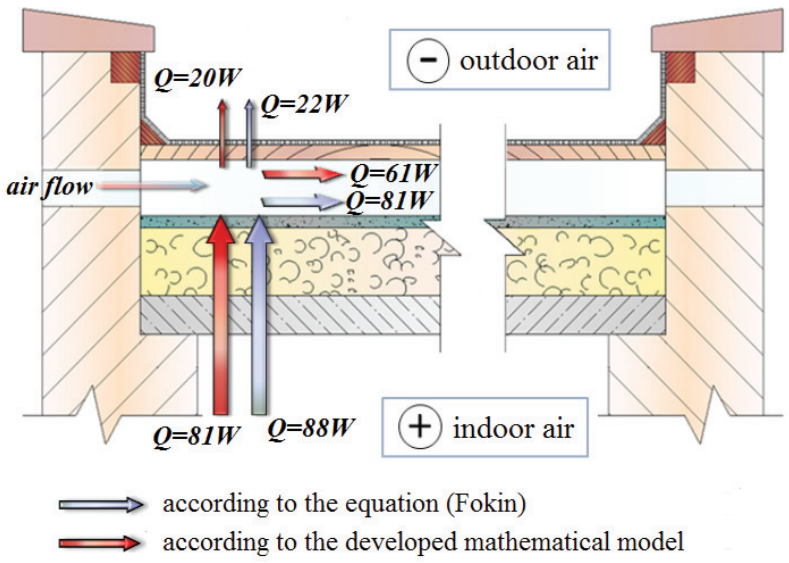

Fig. 3. Comparison of heat flows (winter)

- Heat flow for the heating of the air moving along the attic space

$$
\begin{aligned}
& Q_{a}=c \cdot G \cdot \Delta T a=c \cdot G \cdot\left(T a_{x=L}-T a_{x=0}\right)= \\
& 1005 \cdot 0.0294 \cdot(-5.75-(-8.5))=81 \mathrm{~W} ;
\end{aligned}
$$

- Heat flow from the attic space to the outside ambient

$$
\begin{aligned}
& Q_{a-e}=U_{a-e} \cdot a \cdot b\left(T a_{m}-T_{e}\right)=7 \cdot 0.8(-6.96- \\
& (-8,5))=22 \mathrm{~W} ;
\end{aligned}
$$

Heat flows balance

$$
Q_{a-e}+Q_{a} \neq Q_{i-a}, \quad 22+81 \neq 88 .
$$

On the basis of the comparison, it can be concluded that the air temperature, calculated using different mathematical models coincide with a sufficient degree of satisfaction. But it should be noted that the condition of equality of the heat flows balance using the method given in reference (Fokin 1973) is not satisfied.

The calculation results obtained with the use of the developed mathematical model (2) or (3), were also

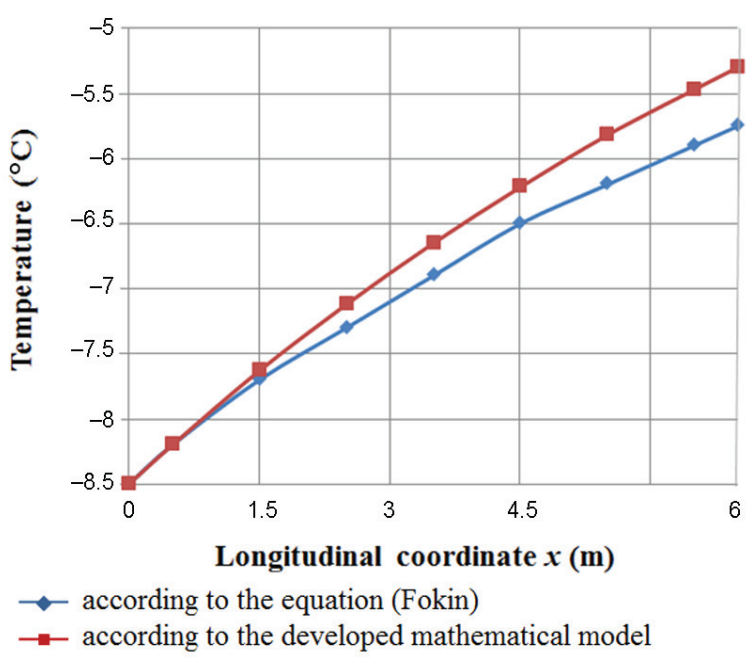

Fig. 4. Comparison of air temperature in the attic space (winter)

compared with the experimental data (Zender-Swiercz, Piotrowski 2010).

The experimental data has been obtained by the authors (Zender-Swiercz, Piotrowski 2010) as a result of in-situ measurements at the end of January and the beginning of February 2009. Measurements were carried out for 12 days. For the comparison, a random period of the length of one day was selected. The results of the comparison are shown in Figure 5. This figure shows a graph of air temperature changes in the attic during the day. The graph was built according to the in-situ measurements (black line). In the same figure, the temperature obtained by calculation using the proposed mathematical model are also marked (blue stars).

The comparison results obtained under the initial data and parameters of the external air during the experiment are represented in Table 2 and Figures 6 and 7.

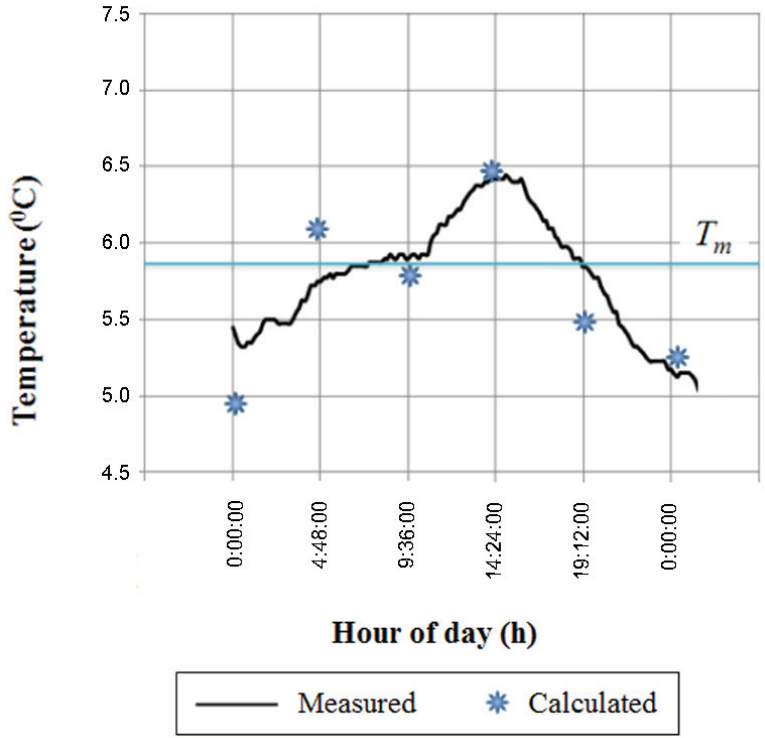

Fig. 5. Comparison of air temperature in the attic (ZenderSwiercz, Piotrowski 2010) (winter) 
Table 2. Some data from comparative thermal calculations of the attic (Zender-Swiercz, Piotrowski 2010)

Heat exchange coefficient from the indoor $U_{i-f}=0.33$ air to the attic floor surface $\left(\mathrm{W} / \mathrm{m}^{2} \cdot \mathrm{K}\right)$

\begin{tabular}{ll}
\hline $\begin{array}{l}\text { Heat exchange coefficient from the } \\
\text { internal roof surface to the outdoor air }\end{array}$ & $U_{r-e}=10$ \\
$\left(\mathrm{~W} / \mathrm{m}^{2} \cdot \mathrm{K}\right)$ & \\
\hline Emissivity & $\varepsilon_{f-r}=0.275$ \\
\hline $\begin{array}{l}\text { Cross-sectional area of the } 4 \text { inlet and } \\
4 \text { outlet grate }\left(\mathrm{m}^{2}\right)\end{array}$ & $A_{o}=4 \times 0.0315$ \\
\hline Dimensional characteristics of the attic $(\mathrm{m})$ & \\
\hline- hydraulic diameter & $D_{h}=2.79$ \\
\hline- length & $L=12.83$ \\
\hline
\end{tabular}

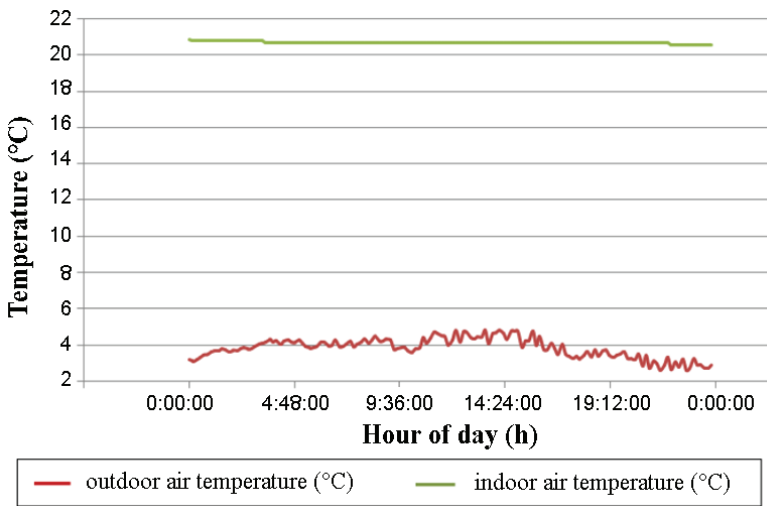

Fig. 6. Measured air temperature (Zender-Swiercz, Piotrowski 2010) (winter)

On the basis of the comparison, it can be concluded that the developed mathematical model for the winter period, written in the form (2) or (3) gives reliable results.

\section{Mathematical model for the summer period}

By analogy to the winter period, the physical and mathematical models of the heat transfer processes in the airspace of the attic were also developed for the summer period.

In the summer season, direct and diffuse solar radiation enters the external roof surface and then comes into the room through the attic floor. The physical model that illustrates the distribution of the heat flow is shown in Figure 8.

The physical model differs from existing similar models for the thermal calculation of the ventilated air spaces in the building structure by its boundary conditions of a heat transfer process at the outer roof surface in the summer period. This process in most scientific literature is considered as the boundary conditions of the third type. At the same time, the concept of the solar temperature is used (Bogoslovskiy 1982; Ciampi 2003; Maczek 2004; Malicki 1980). In fact, the process of heat transfer is much more complicated.

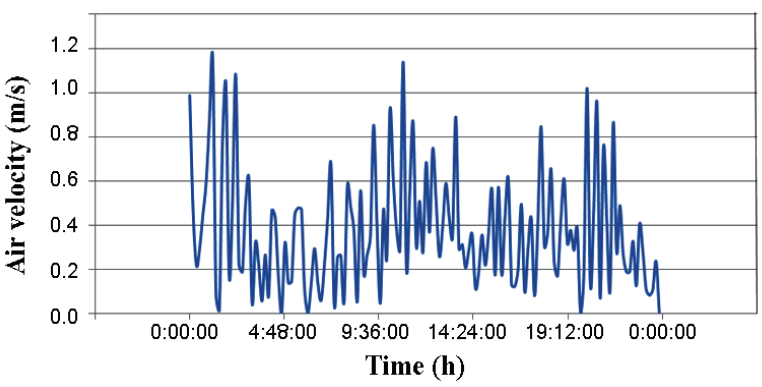

Fig. 7. Measured air velocity in the inlet opening (ZenderSwiercz, Piotrowski 2010) (winter)

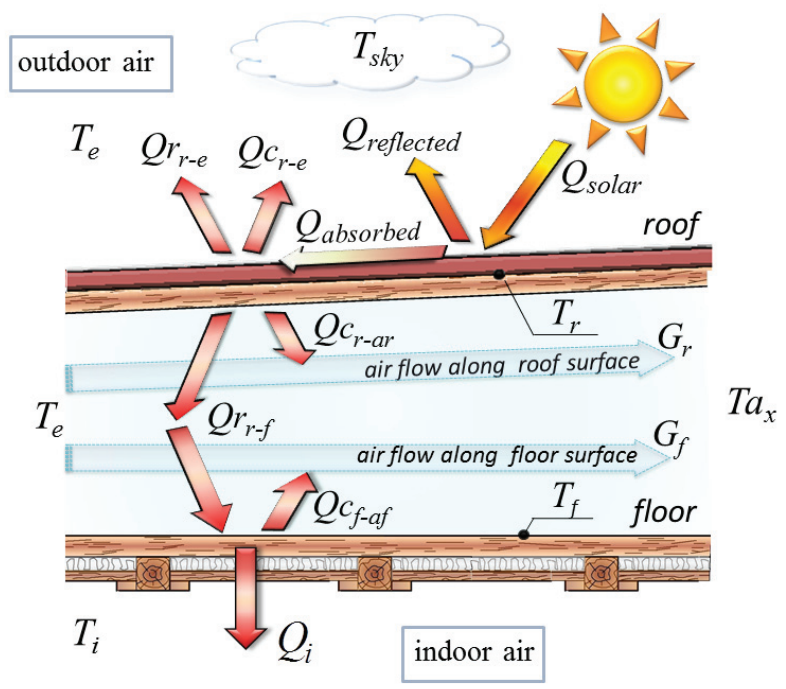

Fig. 8. Scheme of the heat flows in the attic under summer conditions

When the energy flow from the sun $Q_{\text {solar }}$ reaches the surface of the roof in the form of short-wave radiation, one part of it is absorbed by the roof surface $Q_{a b s o r b e d}$ and other part is reflected from it $Q_{\text {reflected }}$. In turn, the surface of the roof radiates a long wave radiation into the outside ambient and in the direction of the attic floor surface $Q r_{r-e}$ and $Q r_{r-f}$.

Furthermore, some part of the heat comes from the outer roof surface into the outside ambient due to convection $Q c_{r-e}$, as well as from the inner roof surface to the air flow moving near this surface $Q c_{r-a r}$. These features are reflected in the first equation of mathematical model (7), which has been developed for the summer season. The mathematical model is based on a physical model (Fig. 8).

Radiative heat flow $Q r_{r-e}$ is a sum of radiative heat flow between the external roof surface and surrounding objects $Q r_{r-a}$ and radiative heat flow between the external roof surface and the sky $Q r_{r-s k y}$. 
The proposed mathematical model for the summer season in the differential form is as follows:

$$
\begin{aligned}
& a_{\mathrm{\rho}} \cdot Q_{\text {solar }}-h c_{e}\left(T_{e r}(x)-T_{e}\right)= \\
& \varepsilon_{e r} \cdot \sigma\left[\left(\frac{T_{e r}(x)+273}{100}\right)^{4}-\left(\frac{T_{\text {surr }}(x)+273}{100}\right)^{4}\right]+ \\
& \frac{T_{e r}(x)-T_{r}(x)}{R_{r}} ; \\
& \frac{T_{e r}(x)-T_{r}(x)}{R_{r}}=\varepsilon_{f-r} \cdot \sigma\left[\left(\frac{T_{r}(x)+273}{100}\right)^{4}-\right. \\
& \left.\left(\frac{T_{f}(x)+273}{100}\right)^{4}\right]+h c_{r}\left(T_{r}(x)-T a_{r}(x)\right) ; \\
& U_{f-i}\left(T_{f}(x)-T_{i}\right)=\varepsilon_{f-r} \cdot \sigma\left[\left(\frac{T_{r}(x)+273}{100}\right)^{4}-\right. \\
& \left.\left(\frac{T_{f}(x)+273}{100}\right)^{4}\right]-h c_{f}\left(T_{f}(x)-T a_{f}(x)\right) ; \\
& h c_{f}\left(T_{f}(x)-T a_{f}(x)\right) b=c G_{f} \frac{d T a_{f}}{d x} ; \\
& h c_{r}\left(T_{r}(x)-T a_{r}(x)\right) b=c G_{r} \frac{d T a_{r}}{d x} ; \\
& \left(\sum \xi_{o} \cdot \frac{v_{o}^{2}}{2} \rho_{e}\right)+\left(\sum \xi+\lambda \frac{L}{D_{h}}\right) \frac{v_{m}^{2}}{2} \rho_{m}= \\
& \left(n_{i n}-n_{o u t}\right) \frac{v_{w}^{2} \rho_{e}}{2}+g H\left(\rho_{e}-\rho_{m}\right),
\end{aligned}
$$

where: $a_{\rho}$ - absorptivity coefficient of the outer roof surface; $Q_{\text {solar }}$ - solar radiation flux density (energy flow from the sun); $U_{i-f}$ - heat exchange coefficient from the indoor air to the attic floor surface; $R_{r}$ - thermal resistance of the roof layers; $h c_{e}$ - convection coefficient near the outer surface of the roof; $H$ - difference in altitude of inlet and outlet vents centres; $\varepsilon_{f-r}$ - equivalent emissivity of the inner surface of the roof and outer surface of the attic floor; $\varepsilon_{e r}$ - equivalent emissivity of the outer roof surface and the outside ambient; $T_{\text {surr }}$ - surrounding radiative temperature (in calculations it is accepted equal to $\left.T_{e}\right) ; T_{e r}$ - temperature at the external roof surface; $\rho_{m, e^{-}}$- mean density of the air in the attic space and outdoor air density; $g$ - acceleration of gravity.

By analogy to the winter period, we obtain the system of Eqns (8) after the integration of the third and fourth differential equations, which characterize the thermal and air regimes in the attic during summer conditions.

$$
\begin{aligned}
& a_{\mathrm{\rho}} \cdot Q_{\text {solar }}-h c_{e}\left(T_{e r}(x)-T_{e}\right)= \\
& \varepsilon_{e r} \cdot \sigma\left[\left(\frac{T_{e r}(x)+273}{100}\right)^{4}-\left(\frac{T_{\text {surr }}(x)+273}{100}\right)^{4}\right]+ \\
& \frac{T_{e r}(x)-T_{r}(x)}{R_{r}} ; \\
& \frac{T_{e r}(x)-T_{r}(x)}{R_{r}}= \\
& \varepsilon_{f-r} \cdot \sigma\left[\left(\frac{T_{r}(x)+273}{100}\right)^{4}-\left(\frac{T_{f}(x)+273}{100}\right)^{4}\right]+ \\
& h c_{r}\left(T_{r}(x)-T a_{r}(x)\right) \text {; } \\
& U_{f-i}\left(T_{f}(x)-T_{i}\right)= \\
& \varepsilon_{f-r} \cdot \sigma\left[\left(\frac{T_{r}(x)+273}{100}\right)^{4}-\left(\frac{T_{f}(x)+273}{100}\right)^{4}\right]- \\
& h c_{f}\left(T_{f}(x)-T a_{f}(x)\right) \text {; } \\
& T a_{f}(x)=T_{f}(x)-\frac{T_{f}(x)-T_{e}}{e^{\frac{h c_{f}}{c G_{f}} x \cdot b \cdot A_{t f}}} ; \\
& T a_{r}(x)=T_{r}(x)-\frac{T_{r}(x)-T_{e}}{e^{\frac{h c_{r}}{c G_{r}} x \cdot b \cdot A_{t r}}} ; \\
& \left(\sum \xi_{o} \cdot \frac{v_{o}^{2}}{2} \rho_{e}\right)+\left(\sum \xi+\lambda \frac{L}{D_{h}}\right) \frac{v_{m}^{2}}{2} \rho_{m}= \\
& \left(n_{\text {in }}-n_{\text {out }}\right) \frac{v_{w}^{2} \rho_{e}}{2}+g H\left(\rho_{e}-\rho_{m}\right) \text {. }
\end{aligned}
$$

The first five equations of the mathematical model (8), which describe a heat balance of the surfaces and air, in the form of a finite difference are as follows:

$$
\begin{aligned}
& a_{\rho} \cdot Q_{\text {solar }}-h c_{e}\left(T_{\text {erm }}-T_{e}\right) \Delta x b= \\
& \varepsilon_{e r} \cdot \sigma\left[\left(\frac{T_{\text {erm }}+273}{100}\right)^{4}-\left(\frac{T_{\text {surr }}+273}{100}\right)^{4}\right] \Delta x b+ \\
& \frac{T_{e r m}-T_{r m}}{R_{r}} \Delta x b ; \\
& \frac{T_{e r m}-T_{r m}}{R_{r}} \Delta x b= \\
& \varepsilon_{f-r} \cdot \sigma\left[\left(\frac{T_{r m}+273}{100}\right)^{4}-\left(\frac{T_{f m}+273}{100}\right)^{4}\right] \Delta x b+ \\
& h c_{r}\left(T_{r m}-T a_{r m}\right) \Delta x b ; \\
& U_{f-i}\left(T_{f m}-T_{i}\right) \Delta x b= \\
& \varepsilon_{f-r} \cdot \sigma\left[\left(\frac{T_{r m}+273}{100}\right)^{4}-\left(\frac{T_{f m}+273}{100}\right)^{4}\right] \Delta x b- \\
& h c_{f}\left(T_{f m}-T a_{f m}\right) \Delta x b ;
\end{aligned}
$$




$$
\begin{aligned}
& h c_{f}\left(T_{f m}-T a_{f m}\right) \Delta x b=c \cdot G_{f}\left(T a_{f e}-T a_{f s}\right) ; \\
& h c_{r}\left(T_{r m}-T a_{r m}\right) \Delta x b=c \cdot G_{r}\left(T a_{r e}-T a_{r s}\right) \\
& 2 \cdot T a_{f m}-T a_{f e}=T a_{f s} ; \\
& 2 \cdot T a_{r m}-T a_{r e}=T a_{r s},
\end{aligned}
$$

where: $T_{\text {erm }}$ - temperature at the outer surface of the roof midpoint of the iterative procedure step.

For a rough estimate of the calculation results of the proposed mathematical model written in the form of (8) or (9), they were compared with the results of example calculations of a ventilated attic space, given in reference (Bogoslovsky 1982). In particular, the values of the heat flows and air temperature in the attic were compared. The results of the comparison of the heat flows are shown in Figure 9, and a graph of the changes in air temperature along the attic space is given in Figure 10. The comparison was made with the following initial data.

The numerical values of the heat flows were determined according to the initial data (Bogoslovsky 1982) under the mean air temperature in the attic space $T a_{m}=31.56{ }^{\circ} \mathrm{C}$ using the following equations:

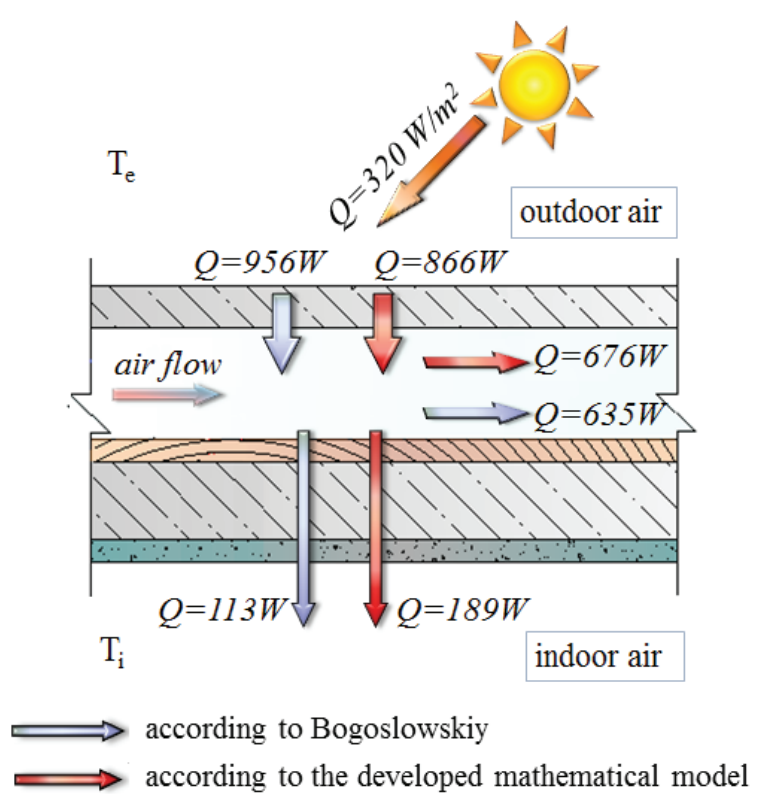

Fig. 9. Comparison of heat flows (summer)
- Heat flow, which enters to the air of the attic space due to the action of solar radiation

$Q_{e-a}=U_{e-a} \cdot L \cdot b\left(T_{s}-T a_{m}\right)=5.13 \cdot 12 \cdot 1(47.1-$

$31.56)=956 \mathrm{~W}$;

- Heat flow, which arrives from the attic space to the room

$$
\begin{aligned}
& Q_{a-i}=U_{a-i} \cdot L \cdot b\left(T a_{m}-T_{i}\right)=2.66 \cdot 12 \cdot 1(31.56- \\
& 28)=114 \mathrm{~W} ;
\end{aligned}
$$

- Heat flow for air heating, while it moving along the attic space

$$
\begin{aligned}
& Q_{a}=c \cdot G \cdot \Delta T a=c \cdot G \cdot\left(T a_{x=L}-T a_{x=0}\right)= \\
& 1005 \cdot 0.215 \cdot(32.94-30)=635 \mathrm{~W} ;
\end{aligned}
$$

Heat flows balance

$$
Q_{a-5}+Q_{a} \neq Q_{i-a}, \quad 114+635 \neq 956 .
$$

In other words, the heat balance equation under the data of the calculation (Bogoslovsky 1982) is not satisfied.

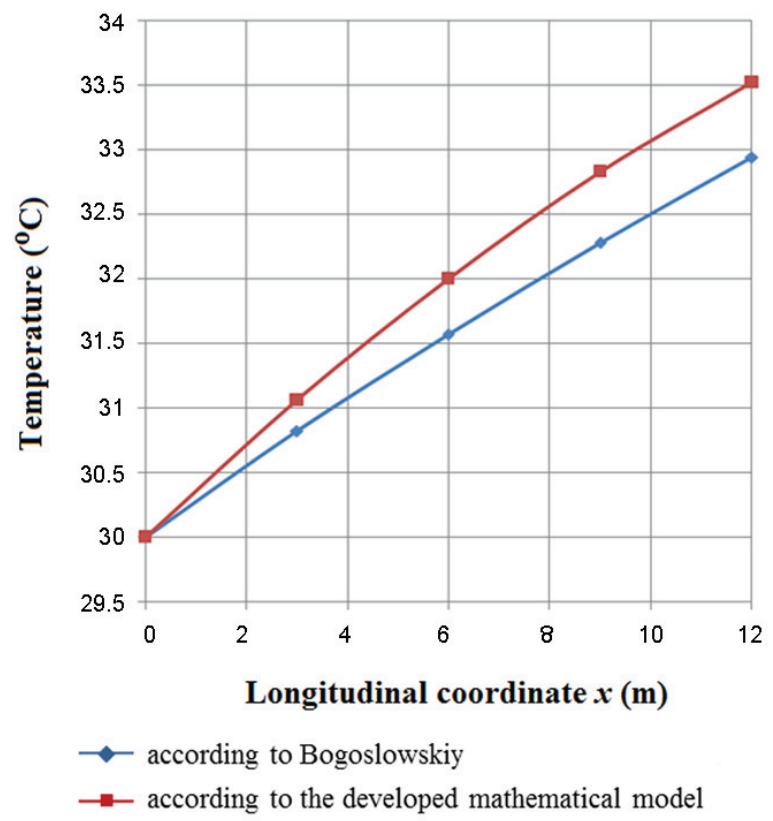

Fig. 10. Comparison of the air temperature in the attic space (summer)

Table 3. Initial data for the comparative calculations of the attic space (according to Bogoslovsky)

\begin{tabular}{llll}
\hline $\begin{array}{l}\text { Heat exchange coefficient from the outdoor } \\
\text { air to the air in attic space }\left(\mathrm{W} / \mathrm{m}^{2} \cdot \mathrm{K}\right)\end{array}$ & $U_{e-a}=5.13$ & $\begin{array}{l}\text { Heat exchange coefficient from the air in attic } \\
\text { space to the indoor air }\left(\mathrm{W} / \mathrm{m}^{2} \cdot \mathrm{K}\right)\end{array}$ & $U_{a-i}=2.66$ \\
\hline Internal air temperature $\left({ }^{\circ} \mathrm{C}\right)$ & $T_{i}=28$ & External air temperature $\left({ }^{\circ} \mathrm{C}\right)$ & $T_{e}=30$ \\
\hline Inlet aerodynamic coefficient & $n_{\text {in }}=0.5$ & Outlet aerodynamic coefficient & $n_{\text {out }}=-0.4$ \\
\hline Wind velocity $(\mathrm{m} / \mathrm{s})$ & $v_{w}=2$ & Dimensional characteristics of the air space & $D_{h}=0.33$ \\
\hline Solar temperature $\left({ }^{\circ} \mathrm{C}\right)$ & $T_{s}=47.1$ & - hydraulic diameter $(\mathrm{m})$ & $L=12 ; b=1$ \\
\hline $\begin{array}{l}\text { Difference in altitude of inlet and outlet } \\
\text { vents centers }(\mathrm{m})\end{array}$ & $H=1$ & - length and width $(\mathrm{m})$ & $\varepsilon_{f-r}=0.275$ \\
\cline { 2 - 4 }
\end{tabular}


Table 4. Initial data for the calculations of the attic space of the academic building

\begin{tabular}{ll}
\hline $\begin{array}{l}\text { Internal air temperature for the winter and } \\
\text { summer seasons }\left({ }^{\circ} \mathrm{C}\right)\end{array}$ & $T_{i}=20$ \\
\hline External air temperature for the winter $\left({ }^{\circ} \mathrm{C}\right)$ & $T_{e}=-20$ \\
\hline $\begin{array}{l}\text { Thermal resistance of the floor layers } \\
\left(\mathrm{m}^{2} \cdot \mathrm{K} / \mathrm{W}\right)\end{array}$ & $R_{f}=1.56$ \\
\hline Thermal resistance of the roof layers $\left(\mathrm{m}^{2} \cdot \mathrm{K} / \mathrm{W}\right)$ & $R_{r}=0.16$ \\
\hline External air temperature for the summer $\left({ }^{\circ} \mathrm{C}\right)$ & $T_{e}=25$ \\
\hline Solar radiation intensity $\left(\mathrm{W} / \mathrm{m}^{2}\right)$ & $Q_{\text {solar }}=320$ \\
\hline $\begin{array}{l}\text { Absorptivity coefficient of the outer surface of } \\
\text { the roof }\end{array}$ & $a_{\rho}=0.91$ \\
\hline Inlet aerodynamic coefficient & $n_{\text {in }}=0.6$ \\
\hline Outlet aerodynamic coefficient & $n_{\text {out }}=-0.4$ \\
\hline Wind velocity $(\mathrm{m} / \mathrm{s})$ & $v_{w}=3$ \\
\hline Cross-sectional area of the inlet and outlet & $A_{o}=0.002$ \\
\hline vents $\left(\mathrm{m}^{2}\right)$ & \\
\hline Dimensional characteristics $(\mathrm{m})$ & $D_{h}=0.33$ \\
\hline- hydraulic diameter & $L=15.3$ \\
\hline- length & $b=1.5$ \\
\hline- width & $a=1.44$ \\
\hline Emissivity height & $\varepsilon_{f-r}=0.85$ \\
\hline
\end{tabular}

\section{Conclusions and recommendations}

Based on the performed theoretical studies and the comparison of the research results, it can be concluded that the developed mathematical models that characterize the thermal-air regime of the attic in the summer and winter periods lead to quite reliable results. They make it possible to better understand and analyse the air-heat processes occurring in the attic. In particular, since the mathematical model allows the determination of the air temperature in the attic and at the internal surface of the roof, using it under the winter conditions makes it possible to evaluate the possibility of moisture condensation on the inner surface of the roof.

To study humidity conditions in the attic, the proposed mathematical model should be considered together with the equation of the humidity balance in the attic. This equation is as follows:

$$
G \cdot d_{e}+W_{d}+W=G \cdot d_{a} .
$$

The specific humidity of the air in the attic:

$$
d_{a}=d_{e}+\frac{W_{d}+W}{G} .
$$

The specific humidity and the temperature of the air in the attic allow us to determine the dew point temperature and compare it with the temperature at the inner surface of the roof $T_{r}$.
The mathematical model for the summer period allows the determination of the necessary rate of air exchange for the excessive solar heat gain removal.

As an example, the influences of the ventilation rate in the attic on the value of the heat flow to the premises of the upper floor for one of the academic buildings of the Kielce University of Technology (Poland) have been analysed. More specifically, the effects of the inlet and outlet vent size in the attic on the value of the heat gains to the premises have been analysed. The calculation results are shown in the graph Figure 11.

Currently, the inlet and outlet ventilation openings with a diameter $0.05 \mathrm{~m}$ are stipulated. In this case the heat flow entering the premises of the upper floor is $11.6 \mathrm{~kW}$. If the size of the inlet and outlet openings is increased up to $\mathrm{d}=0.5 \mathrm{~m}$, the heat gain into the room will be reduced by almost half. On the other hand, with the increase of inlet and outlet vents size, the heat losses under winter conditions will also increase. The graph of the heat losses is shown in Figure 12.

The graphs (Figs 11 and 12) are built with the following initial data.

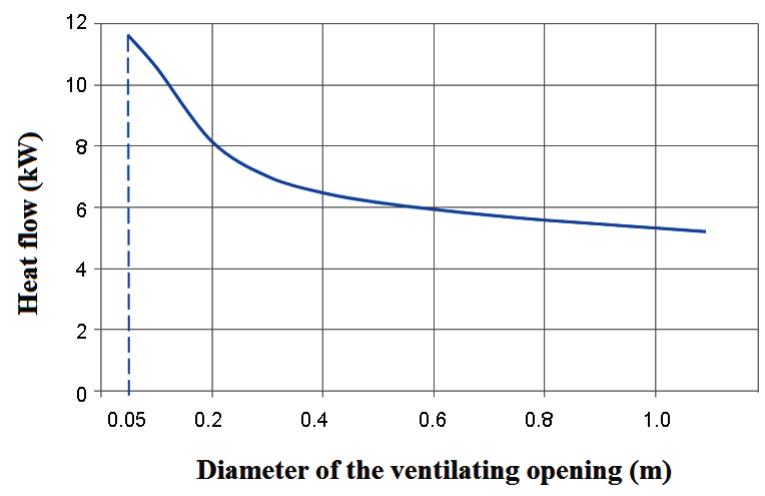

Fig. 11. Heat gain to the premises of the upper floor of the academic building (summer)

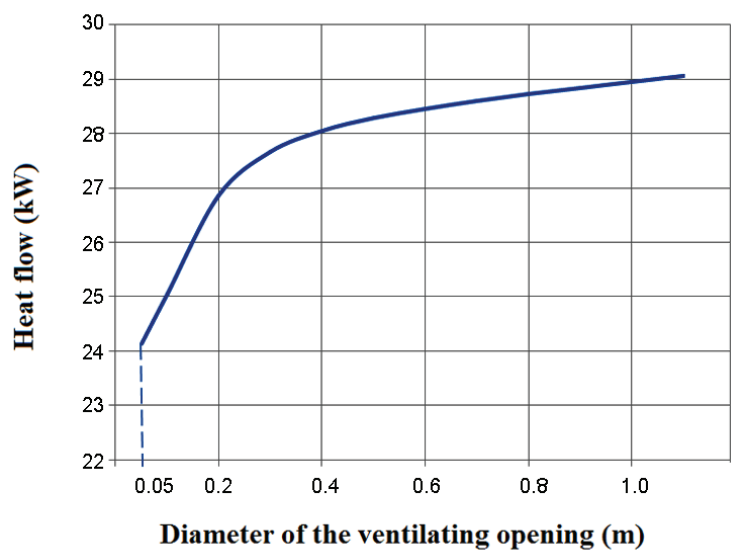

Fig. 12. Heat losses through the roof of the academic building (winter) 
Analysing those two graphs (Figs 11 and 12) together, we can conclude that the cross-section area of the ventilation openings in the attic should be adjustable. The cross-sectional area of the vents should be less in winter and rather more wide in the summer.

It should also be noted that the developed mathematical models allow the assessment of the impact of an attic enclosing structure emissivity on heat losses in the winter and a solar heat gain in the summer periods. They also allow the solutions of other engineering problems related to the attic design.

\section{References}

Berdahl, P.; Fromberg R. 1982. The thermal radiance of clear skies, Solar Energy 29(4): 299-314. http://dx.doi.org/10.1016/0038-092X(82)90245-6

Bogoslovsky, V. N. 1982. Building thermophysics (thermophysical fundamentals of heating, ventilation and air conditioning). Moscow: Higher School. 415 p.

Buga, P. G. 1987. Civil, industrial and agricultural buildings. Moscow: Higher School. 350 p.

Ciampi, M.; Leccese, F.; Tuoni, G. 2003. Ventilated facades energy performance in summer cooling of buildings, Solar Energy 75(6): 491-502. http://dx.doi.org/10.1016/j.solener.2003.09.010

Ciampi, M.; Leccese, F.; Tuoni, G. 2005. Energy analysis of ventilated and microventilated roofs, Solar Energy 79(2): 183-192. http://dx.doi.org/10.1016/j.solener.2004.08.014

Chwieduk, D. 2011. Solar energy for buildings. Warsaw: Arkady publishing. $527 \mathrm{p}$.

EN ISO 6946. Building components and building elements Thermal resistance and thermal transmittance Calculation method, 2008.

Fokin, K. F. 1973. Heat engineering of building envelopes. Moscow: Stroyizdat. 287 p.

Maczek, K. 2004. Air treatment in environmental engineering for ventilation and air conditioning. Cracow University of Technology, PK. 254 p.
Malicki, M. 1980. Ventilation and air conditioning. Warsaw: PWN. 519 p.

Nik, M. V.; Kalagasidis, S. A.; Kjellström, E. 2012. Assessment of hygrothermal performance and mould growth risk in ventilated attics in respect to possible climate changes in Sweden, Building and Environment 55: 96-109. http://dx.doi.org/10.1016/j.buildenv.2012.01.024

Nowak, H. 2001. Modelling of the longwave radiation incident upon a building, Archives of Civil Engineering 47(2): 243-267.

Pogorzelski, J. A. 1976. Building physics. Warsaw: Governmental Scientific Publisher. 268 p.

Shimin, W.; Zhigang, S.; Linxia, G. 2012. Numerical simulation of buoyancy-driven turbulent ventilation in attic space under winter conditions, Energy and Buildings 47: 360-368. http://dx.doi.org/10.1016/j.enbuild.2011.12.012

Stroy, A. F.; Piotrowski, J. Z. 2009. Calculation of attic ventilation by the action of the gravitational pressure, Scientific Papers Collection (Mechanical Engineering and Building) 2(24): 178-184.

Sunwoo, L.; Sang, H. P.; Myong, S. Y.; Kwang, W. K. 2009. An experimental study on airflow in the cavity of a ventilated roof, Building and Environment 44(7): 1431-1439. http://dx.doi.org/10.1016/j.buildenv.2008.09.009

Susanti, H.; Homma, H.; Matsumoto, H. 2011. A naturally ventilated cavity roof as potential benefits for improving thermal environment and cooling load of a factory building, Energy and Buildings 43(1): 211-218.

http://dx.doi.org/10.1016/j.enbuild.2010.09.009

Suvash, C. S.; Patterson, J. C.; Chengwang, L. 2010. Natural convection and heat transfer in attics subject to periodic thermal forcing, International Journal of Thermal Sciences 49(10): 1899-1910.

http://dx.doi.org/10.1016/j.ijthermalsci.2010.05.010

Winiarski, D. W.; O’Neal, D. L. 1996. A quasi-steady-state model of attic heat transfer with radiant barriers, Energy and Buildings 24(3): 183-194. http://dx.doi.org/10.1016/S0378-7788(96)00987-5

Zender-Swiercz, E.; Piotrowski, J. Z. 2010. Calculation of temperature in ventilating roof space, Structure and Environment 1(2): 59-62.

Jerzy Zbigniew PIOTROWSKI. Professor at Swietokrzyski University of Technology, Kielce, Poland. An active Engineer, the author of more than 360 expert reports, 65 publications and 2 monographs. His work at the Civil Engineering Department and his research interests are focused on building physics, climate of rooms, air change in buildings, ventilation and neural networks modelling.

Anatoliy STROY. PhD, DSc. He is the author of 36 articles and co-author of more than 115 research and technical papers, author of 6 books ( 3 of them without co-authors). His field of scientific activities include mathematical modelling of heat and mass transfer processes in building envelopes with the use of renewable energy sources as well as hydraulic processes in the heat supply systems.

Marianna OLENETS. MSc, postgraduate student at the Swietokrzyski University of Technology, Department of Civil Engineering, Kielce, Poland. Publications: 7 articles and presentations in Poland and international proceedings. Research interests: building physics, ventilation and heating systems. Current research interests: mathematical modelling of heat transfer processes and air regime of building envelopes with an open air layer. 